\title{
Method for Monitoring of Managing the Modernization of Regional Economy
}

\author{
T. Krasnova ${ }^{1}, T$. Plotnikova ${ }^{2}, A$. Pozdnyakov ${ }^{1}$, and $A$. Vilgelm ${ }^{1, *}$ \\ * Corresponding author: asvilhelm@gmail.com. \\ ${ }^{1}$ Khakas State University, Abakan, Russia \\ ${ }^{2}$ Siberian Federal University, Khakas Technical Institute, Abakan, Russia
}

\begin{abstract}
This paper proposes a new approach for monitoring of managing the modernisation of regional economic. The model built on proposed methodology will make it possible to smooth out the influence of non-urban areas on the unevenness of economic activity in spatial development. This paper has two goals. The first is to provide a new compilation of data on spatial distribution of economic activity at the subregional level. This data set allows us to monitoring of different indicators within macroregions such as Siberia. The second goal is to construct an instrument that helps to overcome the endogeneity problem using new economic geography hypothesis about the mechanisms of distribution of economic activity. Section 2 describes the data and method that we have proposed, discusses the construction of the Theil indexes using these data at the sub-federal and the sub-regional level. Section 3 presents the correlations between spatial distribution of economic activity and local market potential, discusses the robustness of the results; and the last section concludes.
\end{abstract}

Keywords: economic growth, regional economics, agricultural industry, local markets.

\section{Introduction}

Spatial inequality is a deterrent of socio-economic development regions of Russia. This is especially true of Siberian regions, most of which have resource dependence in economic development. Investment attractiveness is characterized by such similar economic, geographical and other signs as:

- the spatial location relative to other federal districts and proximity to Asian markets;

- low population density and huge distances between cities (The Siberian Federal District occupies $30 \%$ of the territory of the Russian Federation, while the population does not exceed $13 \%$ );

- low efficiency of agriculture in the field of crop production (risk farming zone), extreme climate, remoteness from economic centres, underdeveloped transport, engineering and social infrastructure;

- wealth of natural resources and untapped mineral reserves.

A number of existing studies on the framework of New economic geography (NEG) consider factors affecting the spatial distribution of resources in emerging local markets. For example, the empirical work of Ezcurra et al. [1], Torres-Gutierrez et al. [2] and Abreu et al. [3] substantiates the influence of trade spending, population density, trucking costs, firm size on spatial lag and firm's productivity in developing country's manufacturing sector.

The modernization strategies of Siberian regions provide for the development of competition, the provision of equal opportunities for the modernization of enterprises, the creation of conditions for attracting and developing human resources, stimulating the development of innovative technologies, the development of cooperation of all types (intraindustry, inter-industry and international). Taking into account the resource opportunities, the development drivers are the mining industry and the agro-industrial complex, since with the share of these sectors in the GDP of Siberia $21 \%$, the share of investments in the relevant sectors amounted to more than $33 \%$. Consequently, the study of local markets using output these industries as an example will illustrate not only resource potentials, but also trade and infrastructure potentials.

Enterprises with constant returns to scale and using immobile resources, such as agriculture, may remain concentrated in specific regions [4-9]. To create conditions for the modernization of regional production sectors, the impact of development institutions with business entities on the basis of continuous monitoring indicators is required. Existing methods for estimating and forecasting the potential of local sectoral markets are used in scenario strategic planning, but not in the framework of monitoring.

\section{Materials and Methods}

The paper proposes a new conceptual basis for monitoring, based on modeling the development of regional processes under the influence of factors studied by the NEG. In this regard, the development of tools for factor analysis of modernization processes in inclusive economics becomes more important. Our hypothesis is based on the assertion about the relationship between national development and spatial inequality, proved by Williamson [10]. Proposed model includes shells to perform monitoring of the social and economic status of spatial and sectoral clusters on the 
framework of program-targeted management of socio-economic development. The hierarchical structure of the model consists in a gradual transition of the calculation of the Theil index from a municipality to a regional level which can be calculated as follows:

$$
T^{i}=\sum_{i=1}^{N} \frac{x_{i}}{x} \ln \frac{x_{i}}{x / N}
$$

where $i$ indexes regions, $i$ ranges between 1 and $N ; x_{i}$ is the value of the variable in the region $i$.

A contribution of the present paper is its empirical approach to estimating local markets distance effects in spatial analyses by carefully mapping the spatial returns to scale function. The main specification is the following:

$$
\begin{aligned}
& \ln g d p_{i}^{j}=a_{0}+a_{1} \ln \operatorname{pod}_{i}+a_{2} \ln p o l_{i}+a_{3} \ln t r d+a_{4} \ln t t d+ \\
& +a_{5} \ln t r c+a_{6} \ln f m s_{i}+a_{7} s b b+a_{8} t s b+a_{9} \mathbf{x}+\varepsilon
\end{aligned}
$$

where $g d p_{i}$ is a output of sector; $\operatorname{pod}_{i}$ is a population density; $\operatorname{pol}_{i}$ is a measure of predicted local potential; $\operatorname{trd}_{i}$ is a retail and wholesale trade; $t t d_{i}$ is a exports and imports; $t r c_{i}$ is a trucking; $f m s_{i}$ is a firm size; $s b b_{i}$ is a spatial boundary between regions; $t s b_{i}$ is a spatial transboundary; $\mathbf{x}$ stands for a vector of variables that control for additional predictors that are assumed to have an influence on regional disparities; and $\varepsilon$ is a heteroscedastic error. In this study local market potential as relative notions of space put forward by Garretsen et al. [11]. In this case, due to the difference in potentials during the interaction between the settlements due to the exchange of resources, the effect of agglomeration is achieved:

$$
\text { pol }=\left(\sum \text { pol }_{q}\right)\left(1+\frac{\sum \text { pol }_{k}}{100}\right)
$$

where $\mathrm{pol}_{q}$ is quantitative indicators of state statistical monitoring: labour, output, resource and investment local potential; $\mathrm{pol}_{k}$ is qualitative indicators of state statistical monitoring: infrastructure, innovation and environmental local potential, pol $_{k}=\sqrt[K]{\prod_{k=1}^{K} \text { pol }_{k}}$ and $K$ is amount of indicators of state statistical monitoring of, e.g., dynamic indices of infrastructure development. The important features of the above model are presented below.

\section{Results and Discussion}

Preliminary results obtained by applying the conventional monitoring model show that the existence of highly spatial inequality in potential development of the markets considerable distortion of monitoring results is observed that undermines opportunities when choosing management decisions. Our proposed specification on the field Siberian spatial inequality eliminated this lack of monitoring and enhances the effect of choosing a model for modernization of the regional economy, taking into account spatial and sectoral parameters. A modified monitoring model allows you to adapt the monitoring object to the current analysis, which begins by calculating the Theil's measure of inequality for Siberian regions.

As shown in Table 1, the degree of spatial inequality varies considerably across the sample: from the highest values of the index in urban areas to the lowest values in non-urban areas, and over the three-year period, indicators increased in both groups.

Table 1. Theil index for employment.

\begin{tabular}{|c|c|c|c|c|c|c|}
\hline \multirow{2}{*}{ Indicator } & \multicolumn{3}{|c|}{ Urban area } & \multicolumn{3}{c|}{ Non-Urban Area } \\
\cline { 2 - 7 } & $\mathbf{2 0 1 6}$ & $\mathbf{2 0 1 7}$ & $\mathbf{2 0 1 8}$ & $\mathbf{2 0 1 6}$ & $\mathbf{2 0 1 7}$ & $\mathbf{2 0 1 8}$ \\
\hline Mining industry & 0.195 & 0,196 & 0,196 & 0,072 & 0,072 & 0,071 \\
\hline Agriculture industry & 0,083 & 0,083 & 0,084 & 0,074 & 0,075 & 0,077 \\
\hline
\end{tabular}

Source: Authors.

The Theil index allows considering two hierarchical levels is Siberian macroregion and municipalities. A study of the Theil index at the regional level allows us to identify areas of convergence of economic activity. For a more detailed study, it is necessary to consider the municipal level.

Using obtained data, it is possible to compute spatial distribution of economic activity of different municipalities within regions. To calculate the municipal-level Theil index, the sample size by the number of municipalities in the Siberian macroregion amounted to 3977 units.

For each municipality $j$ of region $i$ in equation (1) need to calculate the Theil index $\left(T_{j i}\right)$ based on the dimensions of diversity identified in this study. The value of the variable in the region $x_{i}$ from the equation (1) was replaced by $x_{i j}$ where $i$ indexes regions (as above); $j$ indexes municipalities; and $x_{i j}$ is the value of the variable in municipality $j$ of region $i$.

The obtained regression results are presented in Table 2 for $\ln g d p$ as dependent variable and Theil index as the measure of spatial distribution. 
Table 2. The impact of regressors on spatial distribution of economic activity: the second stage of the 2SLS regressions*.

\begin{tabular}{|c|c|c|c|c|c|c|}
\hline Regressors & (2.1) & (2.2) & (2.3) & (2.4) & (2.5) & (2.6) \\
\hline Population density & $\begin{array}{l}-0.568^{*} \\
{[0.411]}\end{array}$ & $\begin{array}{c}0.700^{*} \\
{[2.491]}\end{array}$ & $\begin{array}{l}-0.359^{*} \\
{[0.756]}\end{array}$ & $\begin{array}{c}0.039^{*} \\
{[0.239]}\end{array}$ & $\begin{array}{l}1.503^{*} \\
{[2.541]}\end{array}$ & $\begin{array}{r}0.056^{*} \\
{[0.204]}\end{array}$ \\
\hline $\begin{array}{c}\text { Predicted local } \\
\text { potential }\end{array}$ & $\begin{array}{l}-0.297^{*} \\
{[0.456]}\end{array}$ & $\begin{array}{l}1.221^{*} \\
{[2.759]}\end{array}$ & $\begin{array}{l}-0.533^{*} \\
{[0.838]}\end{array}$ & $\begin{array}{l}0.094^{*} \\
{[0.265]}\end{array}$ & $\begin{array}{l}1.968^{*} \\
{[2.814]}\end{array}$ & $\begin{array}{r}0.007^{*} \\
{[0.226]}\end{array}$ \\
\hline $\begin{array}{l}\text { Trade (retail and } \\
\text { wholesale trade) }\end{array}$ & $\begin{array}{l}0.414^{*} \\
{[0,709]}\end{array}$ & $\begin{array}{l}-4.735^{*} \\
{[4.296]}\end{array}$ & $\begin{array}{l}0.661^{*} \\
{[1.304]}\end{array}$ & $\begin{array}{l}-0.001^{*} \\
{[0.411]}\end{array}$ & $\begin{array}{l}-4.168^{*} \\
{[4.381]}\end{array}$ & $\begin{array}{r}0.219^{*} \\
{[0.353]}\end{array}$ \\
\hline $\begin{array}{l}\text { Total trade (exports } \\
\text { and imports) }\end{array}$ & $\begin{array}{l}-0.175^{*} \\
{[0,437]}\end{array}$ & $\begin{array}{l}2.666^{*} \\
{[2.648]}\end{array}$ & $\begin{array}{l}0.077^{*} \\
{[0,804]}\end{array}$ & $\begin{array}{l}0.110^{*} \\
{[0.254]}\end{array}$ & $\begin{array}{l}2.703^{*} \\
{[2.701]}\end{array}$ & $\begin{array}{l}-0.071^{*} \\
{[0.217]}\end{array}$ \\
\hline Trucking & $\begin{array}{l}0.425^{*} \\
{[0.372]}\end{array}$ & $\begin{array}{l}1.749^{*} \\
{[2.254]}\end{array}$ & $\begin{array}{l}0.531^{*} \\
{[0.684]}\end{array}$ & $\begin{array}{l}-0.110^{*} \\
{[0.216]}\end{array}$ & $\begin{array}{l}1.485^{*} \\
{[2.299]}\end{array}$ & $\begin{array}{l}-0.052^{*} \\
{[0.185]}\end{array}$ \\
\hline Firm size & $\begin{array}{l}0.010^{*} \\
{[1.023]}\end{array}$ & $\begin{array}{l}-4.481^{*} \\
{[6.201]}\end{array}$ & $\begin{array}{l}0.069^{*} \\
{[1.883]}\end{array}$ & $\begin{array}{l}-0.288^{*} \\
{[0.595]}\end{array}$ & $\begin{array}{l}-3.869^{*} \\
{[6.324]}\end{array}$ & $\begin{array}{l}0.191^{*} \\
{[0.509]}\end{array}$ \\
\hline $\begin{array}{l}\text { Spatial boundary } \\
\text { between regions }\end{array}$ & $\begin{array}{l}-0.950^{*} \\
{[1.128]}\end{array}$ & $\begin{array}{l}-0.346^{*} \\
{[6.831]} \\
\end{array}$ & $\begin{array}{l}0.041^{*} \\
{[2.074]}\end{array}$ & $\begin{array}{l}0.194^{*} \\
{[0.655]}\end{array}$ & $\begin{array}{l}-0.079^{*} \\
{[6.966]} \\
\end{array}$ & $\begin{array}{r}0.191^{*} \\
{[0.561]}\end{array}$ \\
\hline $\begin{array}{c}\text { Spatial } \\
\text { transboundary }\end{array}$ & $\begin{array}{l}-0.090^{*} \\
{[0.463]}\end{array}$ & $\begin{array}{l}0.504^{*} \\
{[2.804]}\end{array}$ & $\begin{array}{l}0.471^{*} \\
{[0.851]}\end{array}$ & $\begin{array}{l}-0.121^{*} \\
{[0.269]}\end{array}$ & $\begin{array}{l}0.396^{*} \\
{[2.861]}\end{array}$ & $\begin{array}{l}-0.097^{*} \\
{[0.230]}\end{array}$ \\
\hline F-stat (het) & $3.731 * *$ & $1.669^{*}$ & $3.801^{*}$ & $2.523^{*}$ & $8.689^{* * *}$ & $1.639^{*}$ \\
\hline F-stat (hom) & $1.935^{*}$ & $1.470^{*}$ & $3.672 * *$ & $1.686^{*}$ & $3.124 * *$ & $1.484^{*}$ \\
\hline Constant & $\begin{array}{l}7.540^{*} \\
{[7.770]} \\
\end{array}$ & $\begin{array}{l}51.362^{*} \\
{[47.059]} \\
\end{array}$ & $\begin{array}{c}-2.043^{*} \\
{[14.287]} \\
\end{array}$ & $\begin{array}{c}0.838^{*} \\
{[4.512]} \\
\end{array}$ & $\begin{array}{l}35.526^{*} \\
{[47.994]}\end{array}$ & $\begin{array}{l}-2.516^{*} \\
{[3.861]}\end{array}$ \\
\hline Adjusted R-squared & 0.304 & 0.084 & 0.667 & 0.261 & 0.567 & 0.225 \\
\hline Control variables & yes & yes & yes & yes & yes & yes \\
\hline Sample & $\begin{array}{c}\text { all } \\
\text { regions }\end{array}$ & $\begin{array}{c}\text { all } \\
\text { regions }\end{array}$ & $\begin{array}{c}\text { all } \\
\text { regions }\end{array}$ & $\begin{array}{c}\text { all } \\
\text { regions }\end{array}$ & $\begin{array}{c}\text { all } \\
\text { regions }\end{array}$ & $\begin{array}{c}\text { all } \\
\text { regions }\end{array}$ \\
\hline Regions & 12 & 12 & 12 & 12 & 12 & 12 \\
\hline Observations & 3977 & 3977 & 3977 & 3977 & 3977 & 3977 \\
\hline
\end{tabular}

Source: Authors.

Note: * The dependent variable is in (2.4), (2.5), (2.6) Theil index measure, (2.5) is expressed in natural logs. Robust standard errors adjusted for heteroscedasticity in brackets. *, **, and *** indicate significance at the $0.1,0.05$, and 0.01 levels, respectively. „,F-stat (het)" reports F-statistics for the excluded instrument from the first stage under the assumption of heteroscedasticity; and „F-stat (hom)" - under the assumption of homoscedasticity.

First, consider regressions in which the left-hand side includes only $\ln g d p$ (the results are presented in columns (2.1), (2.2) and (2.3), where dependent variable denote, respectively, the natural log of GDP per capita of region, mining sector and agriculture sector). Population density, predicted local potential, trade, trucking and firm size (i.e., number of employees in thousands) are expressed in natural logs. Spatial transboundary and boundary between regions are two dummy variables and their mean is the percentage of observations that take a value of 1 . The sample period is spaned from 2005 to 2018 (source: Federal State Statistics Service of Russia Data). The first stage yields the following results. Population density and predicted local potential has a negative significant effect on labour productivity in region (especially for agriculture sector).

Columns (2.4), (2.5) and (2.6) replace the dependent variable for study of influence the same regressors; in order to exclude endogeneity, for second stage of the 2SLS regressions, testing tools were introduced as a dynamic index for the same indicators in retrospect: the international trade showed a positive correlation, bigger addiction, compared with domestic trade, that means influence interaction of firms in local markets than a population distribution, what means confirmation of the NEG hypothesis about the role of local markets in the spatial development within regions. Firm size and retail and wholesale trade has a negative significant effect on spatial distribution of output in mining and positive of agriculture local markets. Most of these control variables have significant coefficients. The only notable difference between the results with and without these control variables is in the F-statistics for the excluded instrument from the first stage, they do drop once each of these control variables is included. Nonetheless, for the measure of spatial distribution, they still remain sufficiently strong not to worry about weakness of the instrument.

The results presented in Table 2 suggest that firm size and domestic trade in mining industry exerts a negative impact on labour productivity but its impact in agriculture firm is positive. This appears to signal the influence of economies of scale in Siberian agriculture sector, but the absent for mining sector. We find that smaller firms are may ousting larger firms from the market. In the same time, the proximity of local markets to the cross-border regions and high trucking indicates the orientation of mining to export local markets (adjusted $R^{2}=0.567$ ). The results the second stage of the 2SLS regressions suggest that predicted local potential exerts a positive impact on spatial distribution of 
economic activity, stronger in mining. In addition, we estimated all our instrumental variable regressions with generalized method of moments instead of 2SLS and got very similar results with stronger statistical significance.

Study results indicate that the spatial impact of local market factors is most pronounced in the regional output sectors and less pronounced in the regional and clustered level. In any case, when interpreting the information provided by Table 2 , it is important to recall that this analysis allows us to examine the effect of local markets on possible modernization of regional economics. Received results are compatible with a potential positive impact of sectorial modernization processes on regional economic performance in absolute terms.

\section{Conclusions}

The monitoring system for the modernization of economic sectors is formed from indicators with a feedback function at various levels (regional, interregional, country, intercountry). Based on the monitoring results are factors of influence on the development of socio-economic systems which can be used to predict future development. Moreover, the results of intracluster and intra-agglomeration relations must be taken into account when developing roadmaps.

An example of a project that contributes to modernizing the economy of the Siberian region is Yenisei Siberia. Based on investment capital investments in the real sector of the economy, this project provides the spatial development of regions and agglomerations through modernization and creation of new jobs. It is planned to develop such basic industries for Siberia as mining, construction, energy and agriculture. In this case, these regions are the subject of economic development management through infrastructure projects. Thus, in order to ensure uniform development of the regions, modern economic instruments for managing macro-regions are being modernized.

Taking into account the development trends in agricultural and industrial zones development, it is possible to build a strategic plan for socio-economic regional development based on modern economic monitoring tools of managing macroregions. The above methodology, tested in Russian conditions, is suitable for use in the monitoring system both on a regional scale and on municipal level to identify differences and compare industries growth dynamics and the development of regions, since the level of uneven spatial activity of market entities between regions is greater than within one local market. The use of hypotheses of New economic geography as a theoretical basis in the proposed monitoring system allows to take into account infrastructural and resource potentials for increasing the functionality and predictability of monitoring results which is important for investors and government in management.

\section{Acknowledgements}

Authors are grateful to referees and researchers of Samara State University of Economics for helpful comments.

\section{References}

1. R. Ezcurra, A. Rodríguez-Pose, Trade openness and spatial inequality in emerging countries. Spatial Economic Analysis, 9(2), 162-182 (2014).

2. T.P. Torres-Gutierrez, J.A. Ordonez, Agglomeration economies and urban productivity. Region, 6(1), 17-24 (2019).

3. M. Abreu, H.L.F. de Groot, R.J.G.M. Florax, Space and growth: A survey of empirical evidence and methods. Tinbergen Institute Working Paper, TI 04-129/3 (2004).

4. A. Fracasso, G. Vittucci Marzetti, Estimating dynamic localization economies: The inadvertent success of the specialization index and the location quotient. Regional Studies, 52(1), 119-132 (2018).

5. N. Foo, H. Bloch, R. Salim, The optimisation rule for investment in mining projects. Resources Policy, 55, 123-132 (2018).

6. M. Fujita, P. Krugman, Urban systems and regional development. In M. Chatterji (Ed.) Regional Science: Perspectives for the Future (pp. 7-25). London: Palgrave Macmillan (1997).

7. M. Fujita, P. Krugman, A.J. Venables, The spatial economy (MIT Press, Cambridge, MA, 1999).

8. P. Krugman, What's new about the new economic geography? Oxford Review of Economic Policy, 14(2), 7-17 (1998).

9. P.P. Combes, T. Mayer, J.F. Thisse, Economic geography: The integration of regions and nations (Princeton Univ. Press, Princeton, NJ, 2008).

10. J.G. Williamson, Regional inequality and the process of national development: A description of patterns. Economic Development and Cultural Change, 13, 3-47 (1965).

11. H. Garretsen, R. Martin, Rethinking (new) economic geography models: Taking geography and history more seriously. Spatial Economic Analysis, 5(2), 127-160 (2010). 